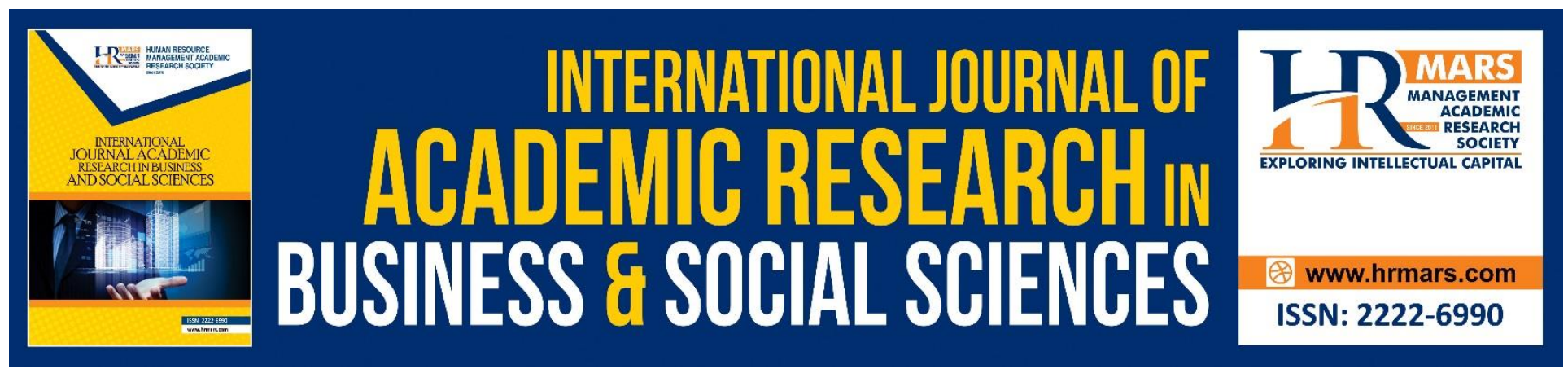

\title{
The Effects of Trauma Focused - Cognitive Behavioural Therapy Group Counselling (Tf-Cbtgc) towards Depression in Bully Victims Among Students
}

Nurul Huda Binti Ishak, Samsiah Mohd Jais, Mohammad Nasir Bistamam

To Link this Article: http://dx.doi.org/10.6007/IJARBSS/v10-i10/8020

DOI:10.6007/IJARBSS/v10-i10/8020

Received: 02 August 2020, Revised: 27 August 2020, Accepted: 17 September 2020

Published Online: 20 October 2020

In-Text Citation: (Ishak, Jais, \& Bistamam, 2020)

To Cite this Article: Ishak, N. H. B., Jais, S. M., \& Bistamam, M. N. (2020). The Effects of Trauma Focused Cognitive Behavioural Therapy Group Counselling (Tf-Cbtgc) Towards Depression In Bully Victims Among Students. International Journal of Academic Research in Business and Social Sciences. 10(10), 887-896.

Copyright: (c) 2020 The Author(s)

Published by Human Resource Management Academic Research Society (www.hrmars.com)

This article is published under the Creative Commons Attribution (CC BY 4.0) license. Anyone may reproduce, distribute, translate and create derivative works of this article (for both commercial and non-commercial purposes), subject to full attribution to the original publication and authors. The full terms of this license may be seen

at: http://creativecommons.org/licences/by/4.0/legalcode

\section{Vol. 10, No. 10, 2020, Pg. 887 - 896}

Full Terms \& Conditions of access and use can be found at http://hrmars.com/index.php/pages/detail/publication-ethics 


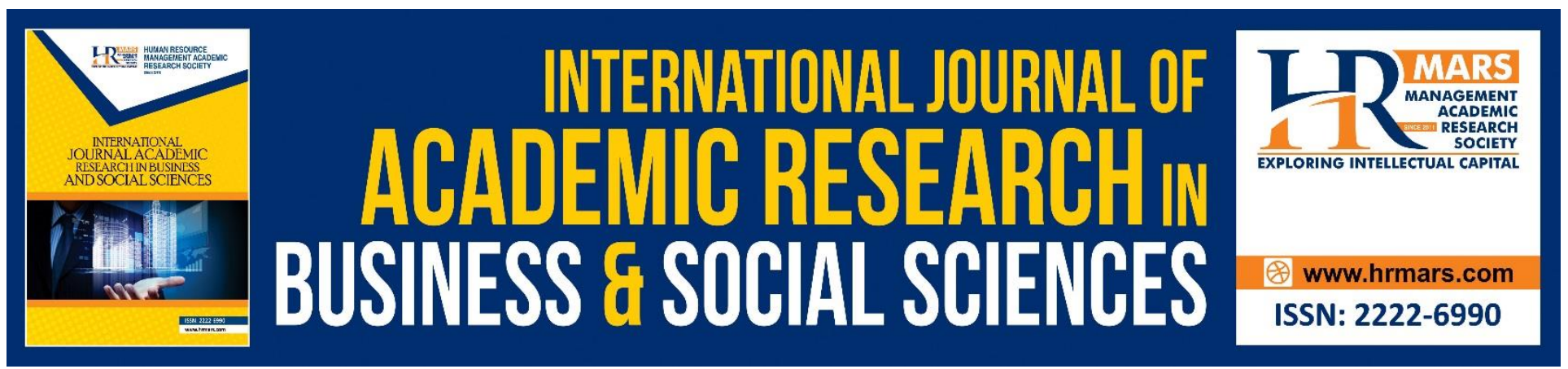

\title{
The Effects of Trauma Focused - Cognitive Behavioural Therapy Group Counselling (Tf-Cbtgc) Towards Depression in Bully Victims Among Students
}

\author{
Nurul Huda Binti Ishak, Samsiah Mohd Jais, Mohammad Nasir \\ Bistamam \\ Faculty of human development, University Pendidikan Sultan Idris \\ Email: daa_6689@yahoo.com.my,samsiah@fppm.upsi.edu.my,nasir.b@fppm.upsi.edu.my
}

\begin{abstract}
This study aims to identify the effects of Trauma Focused-Cognitive Behavioural Therapy group counselling (TF-CBTGC) towards depression in bully victims among students. The research design used was quasi experiment in time series. The research sample consisted of 32 students (16 males and 16 females), who were chosen through purposive sampling in the state of Selangor. The Depression Anxiety Stress Scale 42 and Trauma Focused - Cognitive Behavioural Therapy in Group Counselling module were the instruments for this research. The quantitative data in this experimental research were analysed with SPSS Version 20. Mean descriptive statistics, percentage, standard deviation, and t-test inferential statistics were used to analyse the data. Results from the research shows that Trauma-Focused Cognitive Behavioural Therapy in Group Counselling module is able to decrease the severity of depression among the students who are bully victims, based on their gender. To conclude, by using pairing t-test, it is proven that there is a significant difference on depression between the PRT, PT1, PT2 and PT3 time interval for male bully victims which are: $\{\mathrm{PRT}$ and PT1 $\mathrm{t}$ $(15)=6.86, p<.05)\},\{$ PT1 and PT2 (t $(15)=7.49, p<.05)\},\{\mathrm{PT} 2$ and PT3 (t $(15)=5.09, p<.05)$, and $\{$ PRT and PT3 (t $(15)=9.72, p<.05)\}$. While for female bully victims, the results show:, $\{$ PRT and PT1(t $(15)=6.40, \mathrm{p}<.05)\},\{$ PT1 and PT2 (t $(15)=3.59, \mathrm{p}<.05)\},\{\mathrm{PT} 2$ and PT3 $(\mathrm{t}(15)=6.13, \mathrm{p}<.05)\}$ and $\{$ PRT and PT3 $(\mathrm{t}(15)=10.81, \mathrm{p}<.05)\}$. Based on the analysis of the results, it is shown that TraumaFocused Cognitive Behavioural Therapy in Group Counselling module has helped to decrease the depression level of students who are bully victims. Implication of this research is its ability to indirectly enhance counsellors' efficiency and give new input in overcoming depression among bully victims. An awareness in helping bully victims should be cultivated among counsellors as the victims have to suffer a profound impact on their lives due to bullying.
\end{abstract}

\section{Introduction}

Bully is defined as repetitive negative behaviour from one party to another. The negative behaviour is aimed to give discomfort or difficulties to another party, for example, deserting an individual, 
INTERNATIONAL JOURNAL OF ACADEMIC RESEARCH IN BUSINESS AND SOCIAL SCIENCES Vol. 10, No. 10, 2020, E-ISSN: 2222-6990 @ 2020 HRMARS

beating, showing obscene gestures, or insulting (Olweus, 1994). According to Rigby (2010), bully behaviour is a negative doing physically, verbally, psychologically and includes boycotting and threatening. Research on bully has been done as early as the 1970s (James, 2010), and it has been getting more attention since bully cases are getting more serious and complex as it has a huge impact on the victims (Hassan, 2016).

Bully victims would face mental health problems such as depression and anxiety, that could further lead to suicide. According to Undheim, Wallander and Sund (2016), bully victims will experience higher emotional stress compared to other teenagers who are not involved with bully. Emotional problems and low perseverance in handling stress are among the contributing factors to the bully victims' depression and causing them to become overstressed. Fekkes et al., (2012), stated that bully behaviour brings many negative effects to the victims which include depression and anxiety that cause an increment in problematic behaviours (Parren et al., 2012), which then lead to loneliness and avoidance from school (Kochenderfer \& Ladd, 1996). Sener and Ozan (2013), said bully behaviour is categorized as a worrying state of school violence because the victims are exposed to the after effect of it not only in academic achievement but also in their whole life with a long-term trauma.

Due to this effects on the victims, researchers have built a module to help these bully victims with depression. An intervention called Trauma-Focused Cognitive Behavioural Therapy in Group Counselling module has been developed to help the victims survive and face their lives easier. Trauma-Focused Cognitive Behavioural Therapy in Group Counselling is carried out based on the TFCBT treatment components, summarized by using the acronym PRACTICE; Psycho-education, Relaxation, Affective regulation and modulation, Cognitive coping and processing, Trauma narrative and cognitive processing of the traumatic experience(s), In vivo mastery of trauma reminders, Conjoint sessions, and Enhancing future safety and development. These components were developed by Cohen, Deblinger, and Mannarino (2006).

\section{Objective}

This research aims to measure the effect of Trauma Focused - Cognitive Behavioural Therapy in Group Counselling (TF-CBTGC) module towards students who are bully victims, based on:

1. Descriptive analysis on the differences in mean test measurement that is the intervals between PRT, PT1, PT2, and PT3 on depression based on gender of the bully victims.

2. Inferential analysis on the effect of TF-CBTGC intervention towards depression with time interval tests between PRT and PT1 in bully victims among male students.

3. Analysis on the effect of TF-CBTGC intervention towards depression with time interval tests between PT1 and PT2 in bully victims among male students.

4. Analysis on the effect of TF-CBTGC intervention towards depression with time interval tests between PT2 and PT3 in bully victims among male students.

5. Analysis on the effect of TF-CBTGC intervention towards depression with time interval tests between PRT1 and PT3 in bully victims among male students.

6. Inferential analysis of TF-CBTGC intervention towards depression with time interval tests between PRT and PT1 in bully victims among female students.

7. Analysis on the effect of TF-CBTGC intervention towards depression with time interval tests between PT1 and PT2 in bully victims among female students.

8. Analysis on the effect of TF-CBTGC intervention towards depression with time interval tests between PT2 and PT3 in bully victims among female students. 
INTERNATIONAL JOURNAL OF ACADEMIC RESEARCH IN BUSINESS AND SOCIAL SCIENCES Vol. 10 , No. 10, 2020, E-ISSN: 2222-6990 @ 2020 HRMARS

9. Analysis on the effect of TF-CBTGC intervention towards depression with time interval tests between PRT1 and PT3 in bully victims among female students.

\section{Hypothesis}

Based on the objectives listed, eight hypotheses were formulated in order to achieve those objectives:

i. Null Hypothesis 1 (Ho1): There is no significant difference in the effect of TF-CBTGC intervention towards depression between PRT and PT1 time interval tests in bully victims among male students.

ii. Null Hypothesis 2 (Ho2): There is no significant difference in the effect of TF-CBTGC intervention towards depression between PT1 and PT2 time interval tests in bully victims among male students.

iii. Null Hypothesis 3 (Ho3): There is no significant difference in the effect of TF-CBTGC intervention towards depression between PT2 and PT3 time interval tests in bully victims among male students.

iv. Null Hypothesis 4 (Ho4): There is no significant difference in the effect of TF-CBTGC intervention towards depression between PRT and PT3 time interval tests in bully victims among male students.

v. Null Hypothesis 5 (Ho5): There is no significant difference in the effect of TF-CBTGC intervention towards depression between PRT1 and PT1 time interval tests in bully victims among female students.

vi. Null Hypothesis 6 (Ho6): There is no significant difference in the effect of TF-CBTGC intervention towards depression between PT1 and PT2 time interval tests in bully victims among female students.

vii. Null Hypothesis 7 (Ho7): There is no significant difference in the effect of TF-CBTGC intervention towards depression between PT2 and PT3 time interval tests in bully victims among female students.

viii. Null Hypothesis 8 (Ho8): There is no significant difference in the effect of TF-CBTGC intervention towards depression between PRT and PT3 time interval tests in bully victims among female students.

\section{Methodology}

Design: The researcher chose and applied quasi experimental design in time series aiming to measure the variables of effectiveness on the experimental group (male and female group) repetitively and in a fixed period of time. This research design has been selected as the most suitable design for this research (Raflepour, 2003). The time series quasi experimental design takes a long time to complete and does not have a control group since it only involves treatment group. Data is collected from the research sample a few times after the treatment was given. This design uses multiple crossover techniques that involve a time series treatment.

Instrument: Two instruments were used which include the DASS original version that contains 42 items, developed by Peter Lovinbond of the University of New South Wales, Australia, to measure the level of depression severity of the students who are bully victims. The second instrument was Trauma-Focused Cognitive Behavioural Therapy in Group Counselling Module developed by Jais et al. 
INTERNATIONAL JOURNAL OF ACADEMIC RESEARCH IN BUSINESS AND SOCIAL SCIENCES Vol. 10, No. 10, 2020, E-ISSN: 2222-6990 @ 2020 HRMARS

(2015). However, this module has been modified to suit the subjects of this research and to focus more on the bully victims. Findings from the analysis showed that this module has good content validity with the average score of $86 \%$ or .86 given by six experts on the module.

Location: This experimental research involved students who are bully victims from three schools in the district of Hulu Langat, Selangor.

Subject Selection: The subjects were chosen based on purposive sampling, referring to the sampling procedure where a group of subjects that possess certain characteristics is chosen to be the research respondents (Johnson \& Christensen, 2000). Among the characteristics considered were students who:

i. have obtained an average score on the DASS test.

ii. have had a counselling record of being a victim of violence.

iii. have been once referred because of a bully case.

iv. have been informed to be a victim by the teacher.

v. are observed to be daydreaming and being alone often.

vi. do not have a good relationship with other students in school and are sensitive.

vii. have a weak personality such as passive, shy, and non-energetic in school.

Data collection: Research subjects were administered the DASS questionnaire during four periods of counselling intervention; before the session begins (PRT), during the third session (PT1), after the sixth session (PT2), and finally, after the ninth session was over (PT3).

\section{Results}

a) Descriptive data is presented below to illustrate the effect of Trauma-Focused Cognitive Behavioural Therapy in Group Counselling Module based on the time interval tests of PRT, PT1, PT2 and PT3 towards depression, based on the gender aspect of bully victims among male and female students.

Table 1: The Effect of Trauma-Focused Cognitive Behavioural Therapy in Group Counselling, between time interval tests of PRT, PT1, PT2 and PT3 for bully victims among male and female students.

\begin{tabular}{|c|c|c|c|c|c|c|c|c|c|c|c|c|c|}
\hline $\begin{array}{l}\text { Varia } \\
\text { ble }\end{array}$ & Gender & PRT & PT1 & $\begin{array}{l}\text { Mean } \\
\text { chang } \\
\text { es }\end{array}$ & PT1 & PT2 & $\begin{array}{l}\text { Mean } \\
\text { chang } \\
\text { e }\end{array}$ & PT2 & PT3 & $\begin{array}{l}\text { Mean } \\
\text { chang } \\
\text { es }\end{array}$ & PRT & PT3 & $\begin{array}{l}\text { Mean } \\
\text { change } \\
\mathrm{s}\end{array}$ \\
\hline $\begin{array}{l}\text { Depr } \\
\text { essio } \\
n\end{array}$ & Male & 22.88 & 17.00 & -5.88 & 17.00 & 11.19 & -5.81 & 11.19 & 7.00 & -4.19 & 22.88 & 7.00 & -15.88 \\
\hline & Female & 20.8 & 15.69 & -6.38 & 15.69 & 10.25 & -5.44 & 10.25 & 6.38 & -3.86 & 20.81 & 6.38 & -14.43 \\
\hline
\end{tabular}


INTERNATIONAL JOURNAL OF ACADEMIC RESEARCH IN BUSINESS AND SOCIAL SCIENCES Vol. 10, No. 10, 2020, E-ISSN: 2222-6990 @ 2020 HRMARS

Table 1 shows the effect of Trauma-Focused Cognitive Behavioural Therapy in Group Counselling towards depression between the time interval tests of PRT, PT1, PT2 and PT3 on bully victims among students. Mean TF-CBTGC towards depression between PRT and PT1 time interval for bully victims among male students shows a decrease of -5.81 , and between PT2 and PT3, it is -4.19 . Next, overall, the effect of TF-CBTGC towards depression between PRT and PT3 time interval tests for bully victims among male students shows a reduction with a value of -15.88 . For bully victims among female students, mean TF-CBTGC towards depression between time intervals tests of PRT and PT1 shows a reduction of -5.21 . At the time interval tests between PT1 and PT2, there is a reduction with the value of -5.33 , and next reduction can be seen between the time interval tests of PT2 and PT3, which is 3.86. Overall, the effect of TF-CBTGC towards depression between the time interval tests of PRT and PT3 for bully victims among female students shows a reduction of -14.43 .

b) Inferential analysis was carried out using t-test to answer the hypotheses two to nine, to study the effects of Trauma-Focused Cognitive Behavioural Therapy in Group Counselling based on the time intervals tests between PRT, PT1, PT2 and PT3 towards depression on bully victims among male and female students.

The results of the analysis are as follows:

Table 2: Summary of the effects of TF-CBTGC module towards depression between time interval tests of PRT, PT1, PT2 and PT3 on bully victims among male students

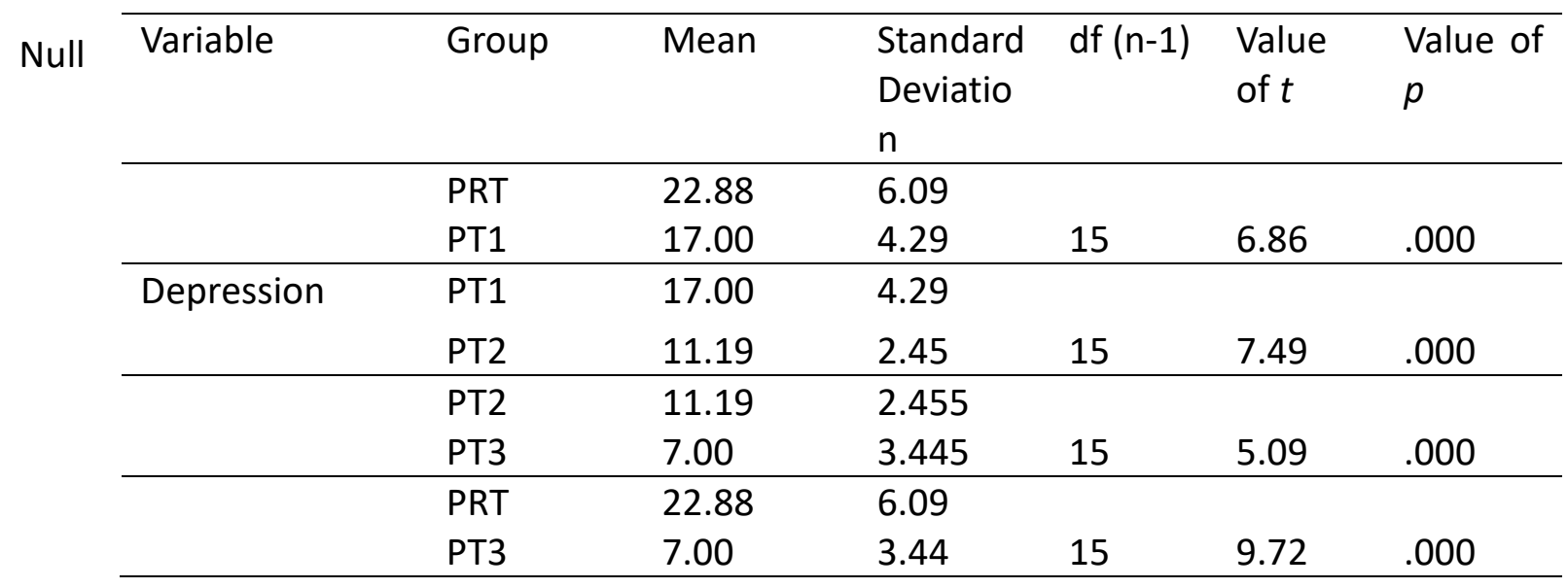

Hypothesis 1 (Ho1): There is no significant difference on the effects of TF-CBTGC intervention towards depression between the time intervals test of PRT and PT1 on the bully victims among male students. Test difference to study the effects of TF-CBTGC module for the time interval of PRT and PT1 shows a t value of $(15)=6.86, p<.05$, that suggests there is a significant difference in the effects of TFCBTGC intervention towards depression between the time interval tests (PRT and PT1) on bully victims among male students. So, null hypothesis 1 is rejected.

Null Hypothesis 2 ( $\mathrm{Ho} 2$ ): There is no significant difference on the effects of TF-CBTGC intervention towards depression between the time interval tests of PT1 and PT2 on bully victims among male students. The difference test to study the effects of TF-CBTGC module for time interval tests between PT1 and PT2 shows a t value $(15)=7.49, \mathrm{p}<.05$, which means there is a significant difference of the 
INTERNATIONAL JOURNAL OF ACADEMIC RESEARCH IN BUSINESS AND SOCIAL SCIENCES Vol. 10, No. 10, 2020, E-ISSN: 2222-6990 @ 2020 HRMARS

effects of TF-CBTGC intervention towards depression between the time interval tests (PT1 and PT2) on bully victims among male students. Therefore, null hypothesis 2 is rejected.

Null Hypothesis 3 (Ho3): There is no significant difference on the effects of TF-CBTGC intervention towards depression between time interval tests of PT2 and PT3 on bully victims among male students. Difference test to study the effects of TF-CBTGC module for PT2 and PT3 time interval tests shows a $t$ value $(15)=5.09 . p<.05$, which confirms that there is a significant difference in the effects of TFCBTGC intervention towards depression between the time interval tests (PT2 and PT3) on bully victims among male students. Therefore, null hypothesis 3 is rejected.

Null Hypothesis 4 (Ho4): There is no significant difference in the effects of TF-CBTGC intervention towards depression between the time interval tests of PRT and PT3 on bully victims among male students. Difference test to study the effects of TF-CBTGC module for the time interval tests between PRT and PT3 shows a t value $(15)=9.72, p<.05$, which indicates that there is a significant difference in the effects of TF-CBTGC intervention on depression between the time interval tests (PRT and PT3) on bully victims among male students. Therefore, null hypothesis 4 is rejected.

Table 3: Summary of the analysis on the effects of TF-CBTGC module towards depression between the time interval tests of PRT and PT1 on bully victims among female students.

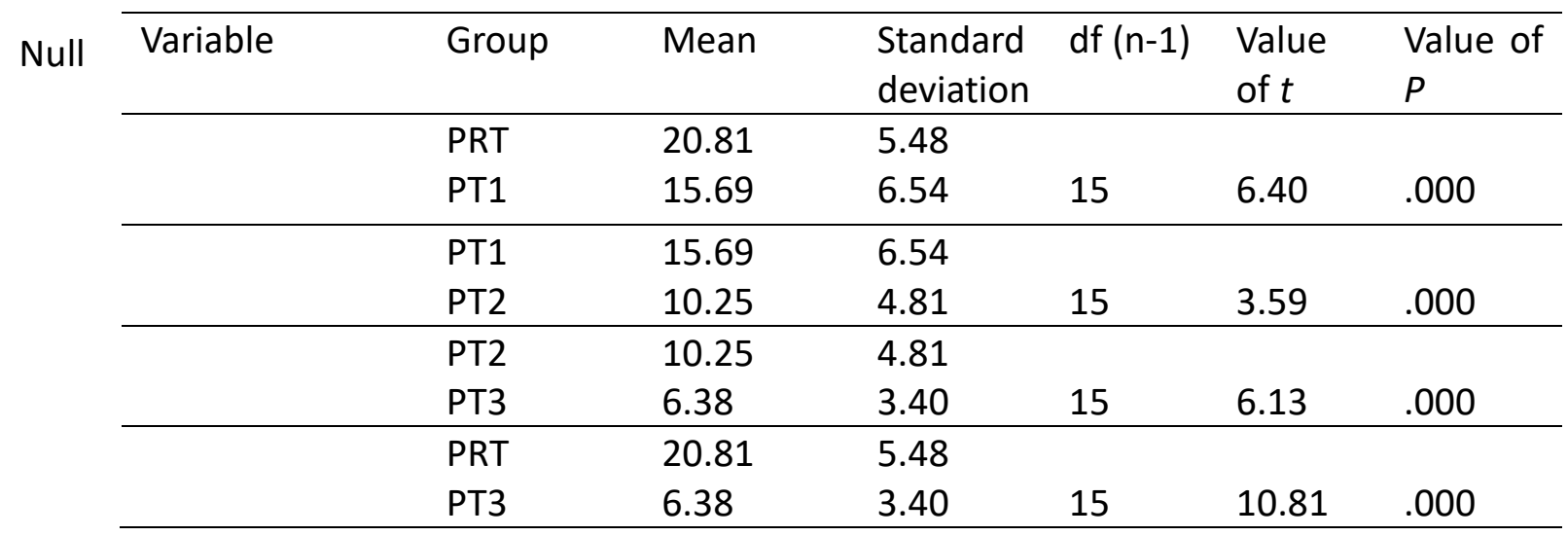

Hypothesis 5 (Ho5): There is no significant difference on the effects of TF-CBTGC intervention towards depression between the time interval tests of PRT and PT1 on the bully victims among female students. The difference test to study the effects of TF-CBTGC module for the time interval tests between PRT and PT1 shows a t value $(15)=6.40, p<.05$, which signifies a significant difference on the effects of TF-CBTGC intervention towards depression between the time interval tests (PRT and PT1) on the bully victims among female students. Therefore, null hypothesis 5 is rejected.

Null Hypothesis 6 (Ho6): There is no significant difference in the effects of TF-CBTGC intervention towards depression between the time interval tests of PT1 and PT2 on bully victims among female students. Difference test to study the effects of TF-CBTGC module for the time interval tests between PRT and PT1 shows a t value $(15)=3.59, \mathrm{p}<.05$, which recommends that there is a significant difference in the effects of TF-CBTGC intervention towards depression between time interval tests (PT1 and PT2) on bully victims among female students. Therefore, null hypothesis 6 is rejected.

Null Hypothesis 7 (Ho7): There is no significant difference in the effects of TF-CBTGC intervention towards depression between the time interval tests of PT2 and PT3 on bully victims among female students. The difference test to study the effects of TF-CBTGC module for the time interval tests 
INTERNATIONAL JOURNAL OF ACADEMIC RESEARCH IN BUSINESS AND SOCIAL SCIENCES Vol. 10, No. 10, 2020, E-ISSN: 2222-6990 @ 2020 HRMARS

between PT2 and PT3 shows a $t$ value 15$)=6.13, p<.05$, which finds that there is a significant difference in the effects of TF-CBTGC intervention towards depression between the time interval tests (PT2 and PT3) on bully victims among female students. Therefore, null hypothesis 7 is rejected. Null Hypothesis 8 (Ho8): There is no significant difference in the effects of TF-CBTGC intervention towards depression between the time interval tests of PRT and PT3, on bully victims among female students. The difference test to study the effects of TF-CBTGC module for the time interval tests between PT2 and PT3 shows t value )15) $=10.81, \mathrm{p}<.05$, which suggests that there is a significant difference in the effects of TF-CBTGC intervention towards depression between the time interval tests (PRT and PT3) on bully victims among female students. Therefore, null hypothesis 8 is rejected.

\section{Discussion}

Quantitative data is collected based on the scores gained from the DASS42 test administered between the time intervals tests of PRT, PT1, PT2 and PT3. The effects of TF-CBTGC module is analysed inferentially using the t-test and the findings of the analysis show that there is a significant difference in the time interval tests between PRT and PT3. Hence, it proves that TF-CBTGC module is effective in reducing depression in bully victims among students. Other than that, descriptively, the changes observed on the trends in PRT1, PT1, PT2 and PT3, are used to see the effects of genderbased group counselling. The result from this research shows that Trauma-Focused Cognitive Behavioural Therapy in Group Counselling (TF-CBTGC) module is able to help reduce the severity of depression on bully victims among students.

\section{Implication}

The result from this research shows that Trauma-Focused Cognitive Behavioural Therapy in Group Counselling (TF-CBTGC) intervention is able to help reduce the severity of depression, anxiety, and stress levels in bully victims among students. All the three elements such as depression, anxiety, and stress relate closely to the symptoms of trauma. Hence, depression, anxiety and stress need to be reduced in order to help the bully victims to undergo their lives with better quality and more positivity. Reduction in the symptoms of depression, anxiety, and stress will help an individual to be free from suicidal thoughts or the feeling of uselessness. The existence of this idea or thoughts to commit suicide put the bully victims in a miserable state of life that is full of suffering and thus, becoming non-effective.

Next, this research will be the foundation for teachers and practitioners of counselling who are interested to know and to deepen their knowledge about Trauma-Focused Cognitive Behavioural Therapy in Group Counselling because TF-CBTGC is not widely used in Malaysia. The effectiveness of TF-CBTGC intervention resulted from this study will be the basic guidance as well as a strategy in the counselling field to help bully victims who experience depression,

anxiety, and stress, by changing their negative thoughts into something good and positive to ensure that they can practice a better and healthier lifestyle. TF-CBTGC intervention module would also be able to assist counselling practitioners on the importance of its proper management in intervention and the correct guidelines to practice this in their sessions.

Overall, this study also helped open a new chapter in the field of counseling. Counseling practitioners can try the techniques and approaches in Trauma Focused - Cognitive Behavioural Therapy helping victims of bullying recover from depression, anxiety and stress because this 
INTERNATIONAL JOURNAL OF ACADEMIC RESEARCH IN BUSINESS AND SOCIAL SCIENCES Vol. 10, No. 10, 2020, E-ISSN: 2222-6990 @ 2020 HRMARS

approach is systematic and structured. Trauma Focused - Cognitive Behavioural Therapy Method is a simple method and has very many implementation strategies and its effectiveness has been tested. Choosing a strategy that suits the client's needs will lead to good results. Therefore, this study has clearly added an intervention approach that can be used to manage the problem of bullying in schools.

\section{Corresponding Author}

Nurul Huda Bt Ishak, Department of Psychology and Counseling, Universiti Pendidikan Sultan Idris, Email: daa_6689@yahoo.com.my

\section{References}

Alloy, L. B., \& Abramson, L. Y. (1979). Judgment of contingency in depressed and no depressed students: Sadder but wiser? Journal of Experimental Psychology, 108(4), 441.

Alloy, L. B., \& Abramson, L. Y. (2016). Learned helplessness, depression, and the illusion of control. Journal of Personality and Social Psychology, 42(6), 1114

Arango, A., Cole-Lewis, Y., Lindsay, R., Yeguez, C. E., Clark, M., \& King, C. (2019). The Protective Role of Connectedness on Depression and Suicidal Ideation Among Bully Victimized Youth. Journal of Clinical Child and Adolescent Psychology, 48(5), 728-739.

https://doi.org/10.1080/15374416.2018.1443456

Baldry, A. C. (2004). The impact of direct and indirect bullying on the mental and physical health of Italian youngsters. Aggressive Behavior, 30(5), 343-355. https://doi.org/10.1002/ab.20043

Bauman, S., Toomey, R. B., \& Walker, J. L. (2013). Associations among bullying, cyberbullying, and suicide in high school students. Journal of Adolescence, 36(2), 341-350

Boyes, M. E., Bowes, L., Cluver, L. D., Ward, C. L., \& Badcock, N. A. (2014). Bullying victimisation, internalising symptoms, and conduct problems in South African children and adolescents: $A$ longitudinal investigation. Journal of Abnormal Child Psychology, 42(8), 1313-1324

Barlow, D.H., Pincus, D.B., Heinrichs, N., \& Choate, M.L. (2003). Anxiety Disorder. In G. Stricker \& T. A. Widiger (Eds.), Handbook of Psychology (p. 119). Canada: John Wiley \& Sons, Inc.

Klomek, A. B., Marrocco, F., Kleinman, M., Schonfeld, I. S., \& Gould, M. S. (2007). Bullying, Depression, and Suicidality in Adolescents. Journal of the American Academy of Child \& Adolescent Psychiatry, 46(1), 40-49. http://doi.org/10.1097/01.chi.0000242237.84925.18

Bylsma, L. M., Taylor-Clift, A., \& Rottenberg, J. (2011). Emotional reactivity to daily events in major and minor depression. Journal of Abnormal Psychology, 120(1), 155

Bylsma, L. M., Taylor-Clift, A., \& Rottenberg, J. (2011). Emotional stress-reactivity and positive affect among college students: The role of depression history. Journal of Emotion, 16(1), 194.

Cary, C. E., \& McMillen, J. C. (2012). The data behind the dissemination: A systematic review of trauma-focused cognitive behavioral therapy for use with children and youth. Children and Youth Services Review, 34(4), 748-757. https://doi.org/10.1016/j.childyouth.2012.01.003

Cohen, J. A., Mannarino, A. P., Murray, L. K., \& Igelman, R. (2006). Psychosocial interventions for maltreated and violence-exposed children. Journal of Social Issues, 62, 737-766.

Cohen, J. A., Mannarino, A. P., \& Murray, L. K. (2011). Trauma-focused for youth who experience ongoing traumas. Child Abuse and Neglect, 35(8), 637-646

Cohen, J. A., Deblinger, E., Mannarino, A. P. (2000). Predictors of Treatment Outcome in Sexually Abused Children. Child Abuse and Neglect, 24, 983-994. 
INTERNATIONAL JOURNAL OF ACADEMIC RESEARCH IN BUSINESS AND SOCIAL SCIENCES

Vol. 10, No. 10, 2020, E-ISSN: 2222-6990 @ 2020 HRMARS

Creswell, J. W. (2003) Research design. Qualitative and Quantitative Approaches.

Creswell, J. (2014). Educational research: Planning, conducting, and evaluating quantitative and qualitative. $5^{\text {th }}$ ed. Boston: Pearson

Creswell, R. (2014). Research design: Qualitative And Quantitative, And Mixed Method Approaches, USA : Sage Publications.

Fekkes, M., Pijpers, F. I. M., \& Verloove-Vanhorick, S. P. (2004). Bullying behavior and associations with psychosomatic complaints and depression in victims. Journal of Pediatrics, 144(1), 17-22. http://doi.org/10.1016/j.jpeds.2003.09.025

James, E. A. (2010). School bullying. University of London. Taken from NSPCC. www.org.uk.inform.

Cohen, J. A., Deblinger, E., Mannarino, A. P. (2012). Trauma-Focused for Children and Adolescents: Treatment Applications: Guilford Publications.

Olweus, D. (1995). Bullying or Peer Abuse at School: Facts and Intervention. America Psyhology Society.

Olweus, D. (2001). Peer harassment: A critical analysis and some important issues. In J. Juvonen \& S. Graham (Eds.). Peer harassment in school: The plight of the vulnerable and victimized, 3-20. NY: Guilford Press.

Jais, S. M., Bistamam, M. N., \& Arip, M. A. S. M. (2015). Modul Kaunseling Kesihatan Mental dan Trauma: Manual Fasilitator. Penerbit UPSI. Universiti Pendidikan Sultan Idris. Tanjung Malim, Perak. ISBN 978-967-0480-87-9.

Sener, G, M. B., Ozan. (2013). The Violence Perception of Teachers and Students at Primary Schools, Sakarya University Journal of Education, 3/1 (Nisan/April 2013) ss. 7-20.

Undheim, A. M., Wallander, J., \& Sund, A. M. (2016). Coping Strategies and Associations With Depression Among 12- to 15-Year-Old Norwegian Adolescents Involved in Bullying. The Journal of Nervous and Mental Disease, 204(4), 274-279. https://doi.org/10.1097/NMD.0000000000000474 